\title{
COMPARISION OF FOUR FOLIAR AND WOODY BIOMASS ESTIMATION METHODS APPLIED TO OPEN-GROWN DECIDUOUS TREES
}

\section{by Paula J. Peper and E. Gregory McPherson}

Abstract. Concern about global climate change and the effects that increasing atmospheric carbon dioxide could have on the earth has risen in recent years. Methods for accurately and efficiently quantifying carbon storage and annual carbon fluxes are needed to determine what role urban forests may have in reducing levels of atmospheric $\mathrm{CO}_{2}$. This will require the development of techniques for estimating foliar and woody biomass of individual trees. In this study, 2 sampling methods and 2 regression formulas for estimating foliar and above-ground woody biomass were tested against the actual above-ground biomass of 8 opengrown deciduous trees ( 2 species). There was no significant difference between one of the subsampling methods and actual foliar, woody, and total above-ground biomass. There were indications that the method's precision in estimating foliar biomass could be improved by modifying the sampling method.The second sampling method predicted foliar biomass of heavily pruned trees within $8 \%$ of actual measurements. For unpruned or lightly pruned trees, one of the regression equations showed no significant difference between estimates of foliar biomass and actual biomass.

Keywords. Allometry; carbon; subsampling; surrogate; urban forest; crown

International concern over reducing the greenhouse gases contributing to global climate change has increased interest in estimating carbon dioxide sequestration in urban trees (Jo and McPherson 1995). Techniques that can better estimate $\mathrm{CO}_{2}$ uptake and storage by urban trees, and how these capacities change over time, are necessary to determine the role urban forests can have in mitigating $\mathrm{CO}_{2}$ emissions. The problem is that almost nothing is known about urban tree $\mathrm{CO}_{2}$ sequestration because of the lack of information available on foliar and above-ground woody biomass for urban tree species. Because foliar and above-ground woody biomass are key parameters necessary for calculating $\mathrm{CO}_{2}$ sequestration, the development of efficient, nondestructive biomass estimation methods is vital for accurately quantifying the $\mathrm{CO}_{2}$ benefits urban forests provide over time. Accurate information could enable tree and utility managers in planning new plantings and reporting $\mathrm{CO}_{2}$ reductions achieved through investments in urban forests (Rowntree and Nowak 1991; McPherson 1992; Simpson and McPherson 1996).
Current methods used to model urban forest carbon sequestration and uptake consist of applying allometric equations derived for natural forest-grown trees to urban trees (Nowak 1991, 1994). Allometry entails studying the relative growth of a part of a plant as it relates to the entire plant. The equations used in biomass prediction typically use measurements of diameter at breast height (dbh), tree height, and crown dimensions to generate above-ground biomass estimates. Research conducted in urban settings on estimation methods has been limited. Nowak (1994) found that allometric equations for forest-grown trees overestimated urban tree biomass. Estimates were multiplied by a factor of 0.8 to adjust for the overage. Because carbon uptake is generally calculated as $50 \%$ of the biomass, overestimations in biomass would result in overestimations of carbon uptake.

For this study, we tested 2 allometric equations. One was developed by Nowak (1996) and is the only one to date based on measurements taken from opengrown trees (in urban areas) rather than forest trees. In direct contrast, the second allometric method chosen was developed from trees in forests in the northeastern United States (Harris et al. 1973). Because forest-developed equations continue to be the primary method of estimating carbon uptake, it is necessary to assess their applicability to trees grown in climate zones milder than the those previously tested in the Midwest. We selected the Harris equation because it was developed from data collected on a wide range of species, with individual trees representing a range of size classes, soil conditions, and competition levels. Because species diversity tends to be great within urban forests (e.g., > 320 spp in Oakland, California; $120 \mathrm{spp}$ in Sacramento), any allometric method selected for testing from rural forests should include as broad a range of species and conditions as possible.

Additionally, trees in urban areas range from unpruned (e.g., residential yard trees, urban riparian areas, and woodlands within parks) to heavily pruned (e.g., street trees, trees beneath utility lines), making it necessary to include representatives from both populations in any biomass estimation study. Methods developed for estimation purposes must be either directly 
applicable to pruned trees or be capable of being adjusted through the development of site factors for various pruning levels.

We also selected 2 subsampling techniques for testing (Valentine et al. 1984, 1994). The assumption was that subsampling methods might produce accurate estimates because they collect leaf and wood data directly from the trees in question. The first of the selected methods, hereafter referred to as the subsampling method, uses randomized branch sampling and importance sampling to provide unbiased estimates of foliar and woody biomass (Valentine et al. 1984). DeGier and Kaboré (1993) employed this method to assess woody biomass in forests in Africa and the Netherlands. Through regression analysis, they showed that a measure of $\mathrm{dbh}$ was adequate to estimate forest woody biomass.

The second sampling technique, referred to as the surrogate method, is based on the hypothesis that the cross-sectional area of the trunk measured directly below the first set of branches is a surrogate for foliar dry matter on an individual tree (Valentine et al. 1994). The concept that weight of the stems and leaves existing above a certain horizontal level in a tree is always proportional to cross-sectional area of the stems and branches found at that level was developed by Shinozaki et al. (1964) and has been successfully applied to various conifers and hardwoods and further modified (Valentine et al. 1984; DeGier and Kaboré 1993).

Essentially, if either of these 2 sampling methods produces precise estimates, we could use regression analyses to determine whether a simple (and easy to obtain) measure of $\mathrm{dbh}$ alone is an adequate variable to use for estimating urban tree foliar and woody biomass.

\section{Objectives}

The primary objective of this pilot study was to test 2 sampling and 2 allometric methods against the total destructive harvest of 8 trees ( 6 mulberries and 2 black cherries) to determine which method(s) produces estimates that are not significantly different from actual measures of foliar, woody, and total above-ground biomass. This is a first step toward finding an accurate and efficient technique for determining, nondestructively, the biomass of a wide variety of opengrown, deciduous urban trees.

\section{Methods}

Study site. Complete destructive sampling of 8 open-grown trees was begun in July 1995 and completed in early October 1995 at the Solano Urban For- est Research Area (SUFRA) at Solano Community College near Fairfield in Northern California. A residential community borders 2 sides of the site, which is commonly used as a park by local residents.

The study included 8 trees: 6 white mulberries (Morus alba) and 2 Chisos cherries (Prunus serotina var. rufula) planted at the site from 18.9- $\mathrm{L}$ ( 5 gal) containers in 1985 and 1986, respectively. The mulberry trunk dbh's ranged from 12.9 to $19.4 \mathrm{~cm}$ (5.1 to $7.6 \mathrm{in}$.). Total tree height and crown width ranged from 4.4 to $8.1 \mathrm{~m}$ (14.5 to $26.7 \mathrm{ft}$ ) and 6.1 to $8.25 \mathrm{~m}$ (20.1 to 28.1 $\mathrm{ft}$ ), respectively. Tree shape was ellipsoidal; however, the prevailing southwest winds in the area had produced crowns that were wider on the northeast sides of the trees than on the southwest. The trees tended to have long, leggy upper branches with many gaps.

The cherry crowns exhibited no shaping effects from the wind and were vertically ellipsoidal with trunk diameters of 20.4 and $20.9 \mathrm{~cm}$ ( 8 and $8.2 \mathrm{in}$.) at breast height. Cherry tree heights were 7.5 and $7.7 \mathrm{~m}(24.8$ and $25.4 \mathrm{ft}$ ) and crown widths were both $4.6 \mathrm{~m}$ (15.2 $\mathrm{ft}$ ). The mulberries were pruned 2 years after planting to remove small branches and suckers from the lower $0.75 \mathrm{~m}(2.5 \mathrm{ft})$ of the boles. The cherries were more extensively pruned to increase crown density and improve their form as landscape trees. These 2 trees were included in the study because they represent many urban street trees, as well as trees growing beneath utility lines, that receive regular pruning.

The study trees were randomly selected from limited populations of 12 mulberry and 5 cherry trees, respectively. The trees were remnants from previous studies conducted at the site. Three received regular irrigation for 24 hours every 10 days and fertilization twice each year for 3 years postplanting only. Subsequently, seasonal rains provided their sole water source. Soil at the site was a deep, well-drained alluvial soil typical of soils in the Class I Yolo Series (Soil Conservation Service 1977).

General data collection. All sampling of the trees took place at the research site before complete destructive harvest. Before sampling, the following dimensions were measured for each tree: 1) dbh (cm), 2) tree height $(m), 3$ ) bole height $(m), 4)$ crown height $(\mathrm{m}), 5)$ crown diameter $(\mathrm{m})$ in 2 perpendicular directions, and 6) crown shape-listed as either paraboloid or vertical ellipsoid (Burkman et al. 1993).

Nowak regression equation for foliar biomass. The Nowak equation estimates total leaf dryweight biomass (Nowak 1996). The equation is of the form:

$\ln Y=1.9375+0.4184 H+0.6218 D+3.0825 S+-0.0133 C$ 
where In is a normal logarithmic transformation, $Y$ is leaf dry-weight biomass $(g), H$ is crown height $(\mathrm{m}), D$ is average crown diameter $(\mathrm{m}), S$ is percentage of light intensity intercepted by foliated tree crowns (average shading factors), and $C$ is $\pi D(H+D) / 2$, based on the outer surface area of the tree crown (GackaGrzesikiewicz 1980). The back-transformed estimated response, $\hat{Y}$, was multiplied by $e^{\mathrm{MSE} / 2}$ to correct for the bias due to the logarithmic transformation (Baskerville 1972). The correction factor was added to the untransformed estimates (Nowak 1996). Shading factors of 0.78 for Morus alba (McPherson unpublished data) and 0.67 for Prunus serotina, obtained from data collected from prior studies were used with a leaf area study (Peper and McPherson 1998). Data collected in the field included total tree height, height to bottom of crown, crown width in 2 perpendicular directions, and dbh.

Harris equations for predicting biomass. This allometric method estimates stem, branch, and leaf dryweight biomass for hardwoods greater than $10 \mathrm{~cm}(3.9$ in.) dbh (Harris et al. 1973). It requires a measurement of $\mathrm{dbh}$ only. These equations were of the form:

\section{Stem: $\quad$ In $w t=-2.437+2.418 \ln \mathrm{dbh}$ \\ Branch: $\quad$ In $w t=-3.188+2.226 \ln \mathrm{dbh}$ \\ Leaf: $\quad \ln w t=-3.498+1.695 \ln \mathrm{dbh}$}

where In is a normal logarithmic transformation of the associated variable (weight or dbh).

Woody biomass was obtained by adding stem and branch results. Total above-ground biomass was obtained by adding stem, branch and leaf results.

Sampling methods. Both the surrogate and subsampling methods require the selection of a path that extends either from the base of the tree to the tip of a terminal shoot (for subsampling) or from the butt of a first-order branch to the tip of the terminal shoot (for surrogate). The path is a series of connected branch segments (internodes). Data collected from the paths is used to calculate total foliar and woody biomass of the tree.

Subsampling method for foliar and woody biomass. With subsampling, the foliar and woody biomass (above-ground) was estimated by averaging data collected from 2 paths per tree. We selected paths by measuring diameters of the bole and branches at each node. Referencing Figure 1, diameters were taken at the first node (locations $a$ and $b$ ). Also, the lengths of each segment $\left(L_{1}\right.$ and $\left.L_{2}\right)$ were measured with a meter tape and recorded. Both diameters and length measurements were entered into a random-selection computer program we developed based on formulas delineated by Valentine et al. (1984) for path selec- tions. If diameters $a$ and $b$, along with distances $L_{1}$ and $L_{2}$ were entered into the program with the outcome that a was randomly selected, we proceeded up the bole of the tree to the next node and repeated the selection process until the end of the path was reached at terminal shoot $i$. The final segment in each path was always a terminal segment, in this case branch $i$. The selected terminal branch was cut off and the fresh weight recorded. Because of the randomness of the selection methods, there was equal probability for branch $b, d, f, g$, $i$, or $j$ to be selected and cut for weighing.

The formulas used to inflate the weight of the terminal branch to obtain whole tree foliar biomass using the field measurements of the branch weight are described by Valentine et al. (1984), as are the formulas for obtaining woody biomass. Essentially, the fresh woody weight of the tree was calculated from a disc cut at a randomly selected location along the path.

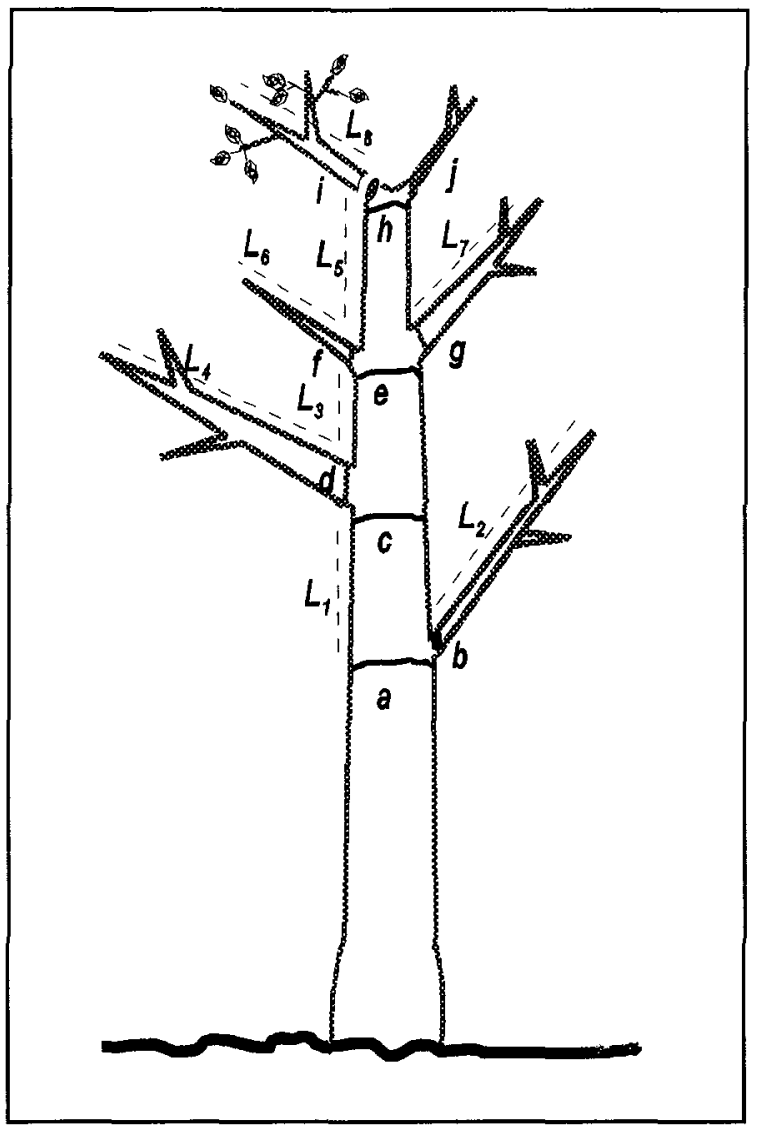

Figure 1. Identification of tree branches for selecting a path from base of tree to terminal shoot. Segments in path were selected using measurements of diameter $(a, b, \ldots)$ and length $\left(L_{1} \ldots L_{8}\right)$. 
We selected cutting points along our 2 paths for each tree and cut and weighed the disks. Disks were reweighed after drying $\left(65^{\circ} \mathrm{C}\left[149^{\circ} \mathrm{F}\right]\right.$ for 72 hours) to obtain a fresh weight:dry weight ratio. Total woody dry weight of the tree was estimated using field measurements of the weight and thickness of each disk along with measurements of diameter and lengths taken for every segment in the path (see Valentine et al. 1984 for specific formulas).

Surrogate method for estimating foliar biomass. Foliar biomass estimates were obtained using the stratified, multi-stage, probability sampling methods described by Valentine et al. (1994). This required that each tree crown be horizontally stratified into thirds. The diameter of each live branch in each stratum was measured, and 2 first-order branches from each stratum was randomly selected with probability proportional to the diameter squared. Similar to the subsampling method, randomized branch sampling was conducted on each selected branch to determine a path from the butt of the first-order branch to the tip of a terminal shoot.

Foliage was removed from each internodal segment of the branches, weighed fresh, then dried at $65^{\circ} \mathrm{C}$ for 24 hours and re-weighed. Foliar dry matter was estimated for each stratum by multiplying the foliage dry weight from each segment by the reciprocal of the segment's probability of selection, then summing these inflated weights within each path and averaging the sums for the two paths. Summing the results for the 3 strata provided the estimated foliar biomass for the tree.

Actual biomass measurements. After all path data were collected, the remainder of the leaves on the 8 trees were stripped from the trees for a $100 \%$ destructive sample. These leaves were dried $\left(65^{\circ} \mathrm{C}\right.$ for 24 hours) and weighed; the results were added to previously measured path sampling leaf weights to obtain total actual foliage dry weight for each tree. Trees were then cut at ground level and fresh weights of the bole, limbs, and all other above-ground woody material measured within $0.001 \mathrm{~kg}$ using a digital scale. Total actual woody dry weight was inferred using the fresh weight:dry weight ratios for each tree.

Data analysis. Paired t-tests (at $\alpha=0.05$ ) were used to test the null hypothesis that there was no significant difference between means from each estimation method and actual biomass.

\section{Results}

Foliar biomass. All 4 foliar biomass estimates were tested against actual biomass (Table 1). With the exception of the subsampling method, all methods underestimated foliar biomass of both species (Figure 2).
Table 1. Sample means, errors, and t-test results for 6 mulberry and 2 Chisos cherry trees $(n=8)$ and separate results for the mulberry trees $(n=6)$.

\begin{tabular}{|c|c|c|c|c|}
\hline \multirow[b]{2}{*}{ Method } & \multicolumn{2}{|c|}{$\begin{array}{l}\text { Mean biomass } \\
\text { for all trees }\end{array}$} & \multicolumn{2}{|c|}{ Morus only } \\
\hline & $(\mathrm{kg})$ & se & $(\mathrm{kg})$ & se \\
\hline \multicolumn{5}{|l|}{ Foliar } \\
\hline Actual & 12.86 & 1.38 & 14.01 & 1.58 \\
\hline Harris et al. & 3.86 & 0.36 & 3.45 & 0.32 \\
\hline Nowak & 9.49 & 1.55 & 10.15 & 2.03 \\
\hline Subsampling & $13.25^{\star}$ & 1.68 & $11.19^{\star}$ & 1.36 \\
\hline Surrogate & 9.46 & 1.26 & 9.75 & 1.7 \\
\hline \multicolumn{5}{|l|}{ Woody } \\
\hline Actual & 88.01 & 11.41 & 82.17 & 14.68 \\
\hline Harris et al. & 114.68 & 14.77 & 97.22 & 12.72 \\
\hline Subsampling & $76.77^{*}$ & 11.93 & $72.88^{*}$ & 10.13 \\
\hline \multicolumn{5}{|c|}{ Total above-ground } \\
\hline Actual & 100.86 & 12.19 & 96.18 & 12.19 \\
\hline Harris et al. & 118.56 & 15.14 & 100.68 & 13.07 \\
\hline Subsampling & $90.02^{\star}$ & 12.14 & 84.07 & 9.84 \\
\hline
\end{tabular}

*Estimate is not significantly different from actual value at $\alpha=$ 0.05 .

The subsampling-foliar estimates were evenly divided between under- and overestimates (Figure 2c), producing a mean estimated biomass for the 8 trees similar to actual mean biomass. Paired t-test results (at $\alpha=0.05$ ) showed no significant difference from actual foliar biomass; however, individual foliar biomass estimates did not increase as actual biomass increased. The t-tests conducted on mulberries only $(n=6)$ also showed no significant difference between the estimate method and actual foliar biomass $(t=1.36$, $P=0.23$ ), but again individual biomass estimates did not increase as actual foliar biomass increased.

The t-test results for the remaining Harris, Nowak, and surrogate foliar estimation methods, whether applied to all trees or mulberries alone, revealed significant differences between estimates and actual foliar biomass (Table 1). Foliar biomass underestimation was most severe for the Harris-foliar method (Figure 2a), with the mulberry biomass estimates showing slight increases as actual biomass increased. The increase in estimated foliar biomass in relation to actual biomass was more discernable for the Nowak and surrogate foliar methods (Figure 2b, d). Both methods produced closer-to-actual estimates for cherry tree foliar biomass than the subsampling-foliar and Harrisfoliar methods. Nowak produced cherry estimates within $8 \%$ and $31 \%$ of measured foliar biomass, while Harris was consistent in producing estimates with $8 \%$ of actual.

Woody biomass. The Harris-woody biomass equation and the subsampling-woody method for es- 


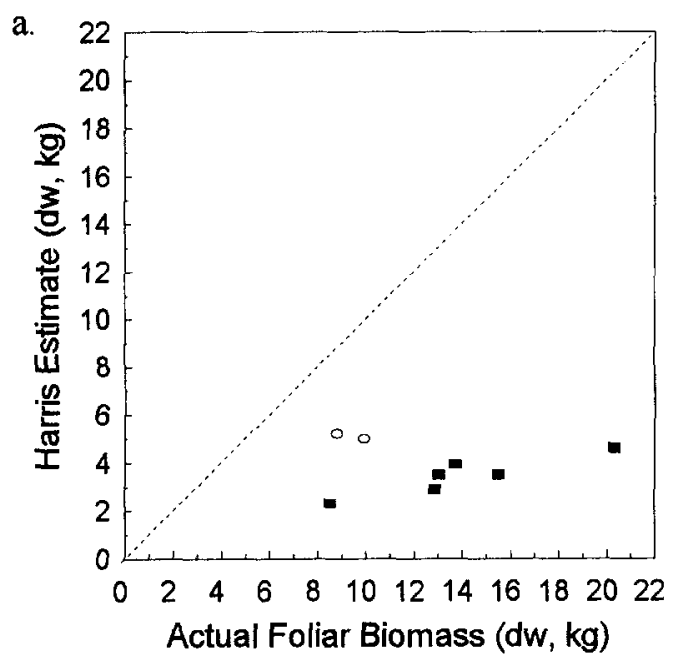

c.

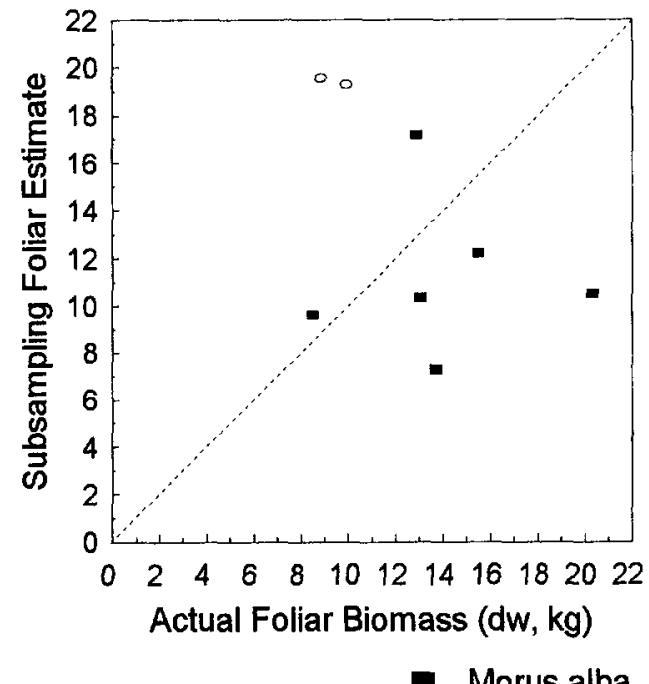

Figure 2. Four foliar biomass estimation methods plotted against actual foliar biomass of 6 mulberry and 2 cherry trees. The subsampling method was not statistically significantly different from measured biomass (comparison of means), but the method was imprecise for estimating individual tree biomass.

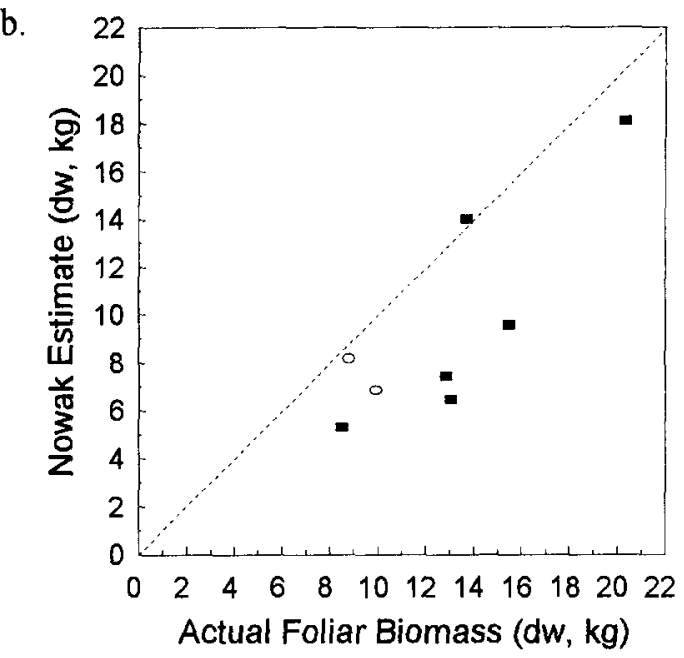

d.




a.

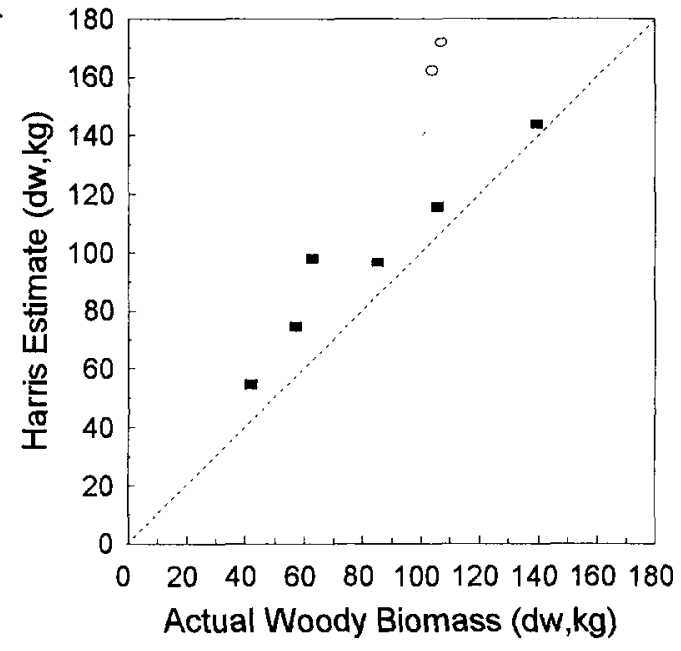

Morus alba

c.

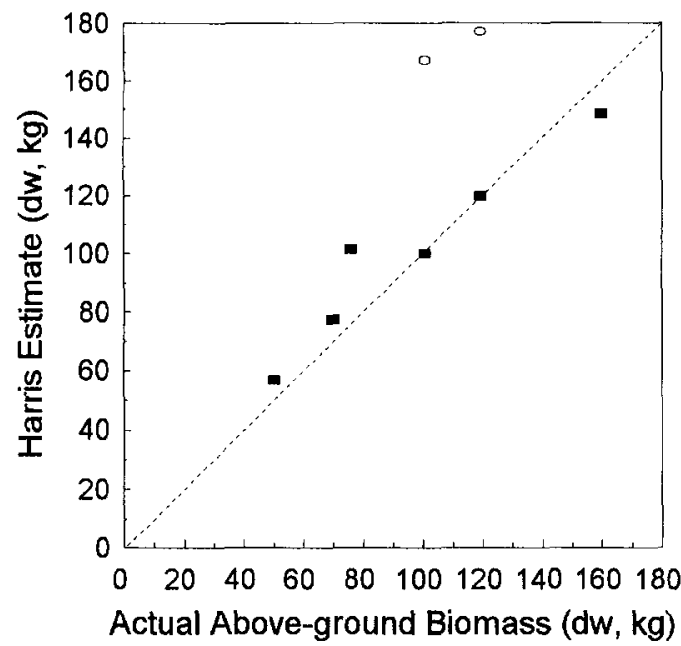

b.

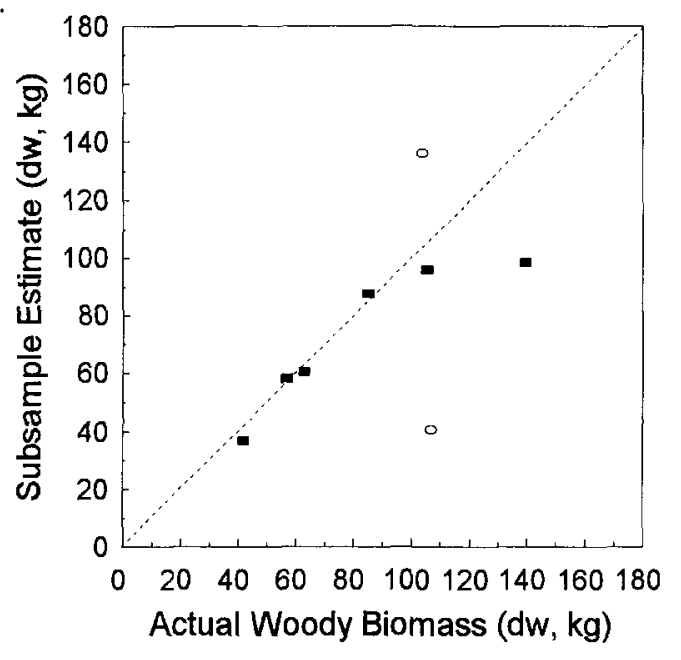

Prunus serotina var. rufula

d.

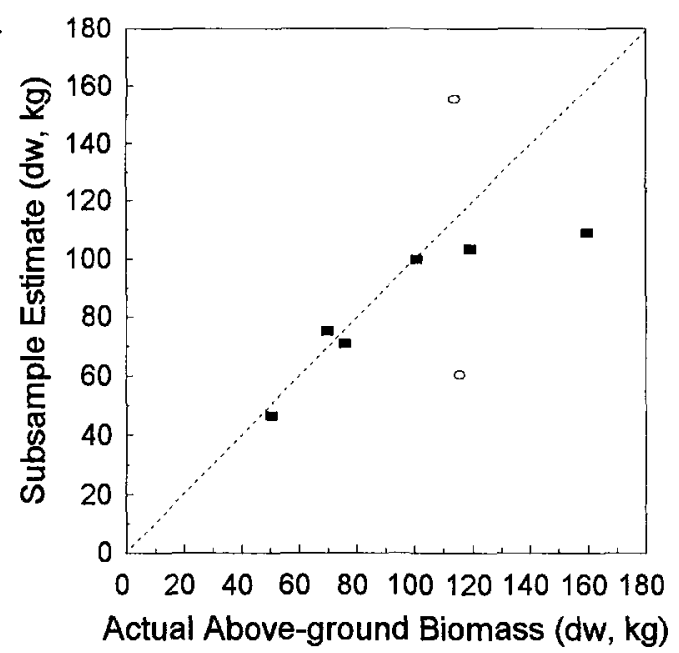

Figure 3. Two woody $(a, b)$ and two total above-ground biomass $(c, d)$ estimation methods plotted against actual biomass. There were significant differences between both woody biomass estimation methods and actual biomass, but no significant difference between the 2 total above-ground estimation methods and actual biomass. 
timating woody biomass were tested against the actual woody dry weights for the 8 trees. The scatter plot for the subsampling-woody estimation technique showed that 5 of the 6 mulberry estimates corresponded closely to actual woody biomass weights (Figure $2 b$ ). Note that the method fairly accurately estimated biomass ( 58 and $60 \mathrm{~kg}[\sim 128$ and $132 \mathrm{lb}])$ for 2 mulberries of similar weights $(\sim 57$ and $63 \mathrm{~kg}[\sim 119$ and $139 \mathrm{lb}$, respectively) but was not accurate in estimating biomass for 12 cherry trees of similar weights (41 and $136 \mathrm{~kg}$ [90 and $300 \mathrm{lb}$ ] versus actual of 107 and $104 \mathrm{~kg}$ [236 and $229 \mathrm{lb}$ ]). However, under- and overestimations counterbalanced one another and no significant difference between the subsampling-woody biomass estimation technique and actual woody dry weight was noted, whether the tests were run on data sets for both species or for the mulberry alone (Table 1).

The Harris-woody equation overestimated weights for all trees (Figure 3a). T-tests showed significant difference between actual woody biomass and the equation estimates for all trees. Figure $2 a$ shows that increases in estimates relate to increases in actual biomass for the mulberries.

Total above-ground biomass. The Harris-total equation and the subsampling-total method were tested against actual biomass for accuracy in estimating total above-ground biomass. There was no significant difference between actual and estimated biomass for the subsampling method tested across both species (Table 1). For the Harris method, there was no significant difference when tested on the mulberries alone. Both methods estimated mulberry tree biomass more accurately than cherry tree biomass (Figure 3c, d).

\section{Discussion}

Tree growth and biomass accumulation are influenced by genetics, climate, soil, moisture, and competition. We can eliminate all but genetics as potential variables influencing our results because the trees were all grown at the same site under the same conditions. They were

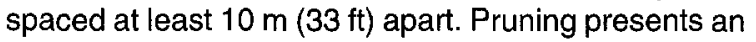
additional variable that we cannot eliminate for the cherry trees since they were heavily pruned in their early years to increase crown density. There are also potential limitations and errors associated with the methods themselves because each is a product of the sample used in its development. Whether that sample was taken from a natural, plantation, or urban forest environment, from a forest canopy or an individual tree crown can affect the method's transferability.

Harris equations. Because the Harris regression equations were developed in the Northeastern United States for use with a wide range of rural rather than urban forest species, transferability possibilities might be expected to be very poor. Our results did show significant differences between all Harris estimates and actual biomass when tested across both species (Table 1). However, there was no significant difference between total above-ground estimates and actual measurements when tested on the mulberries alone, suggesting that the method may be applicable to urban trees that have not been pruned or receive light prunings.

The fact that the estimates for foliar and woody biomass were significantly different from actual measures (while estimates for total biomass were not) indicates a problem with how biomass is partitioned by the equations. Generally, the Harris equations partition more biomass to wood than foliage, assuming that foliage accounts for only $3 \%$ of total aboveground biomass. Our measurements of actual dry weight show that foliage accounted for approximately $13.5 \%$ of total biomass averaged across both species (or $15 \%$ of total mulberry where $n=6$, and $8 \%$ of cherry where $n$ $=2$ ). There may be potential for adjusting the Harris partitioning to account for these differences.

Subsampling. The subsampling method was developed using a sample of 8 trees from a mixed oak stand in the Cockaponset State Forest, Chester, Connecticut and further tested on shrubs and trees (deciduous broad-leaved and conifers) from mixed agricultural/woodland landscapes in The Netherlands and Burkina Faso, Africa. As with the Harris method, subsampling was developed using rural forest stands, but because the method is statistically based to produce unbiased estimates it should be transferable to open-grown deciduous trees in the urban landscape that have not received recent or significant amounts of pruning. This, along with the surrogate method, should produce the most accurate methods because they collect leaf and wood biomass data directly from the tree in question. Indeed, t-tests pairing the subsampling estimates with actual foliar, woody and total above-ground biomass reveal no significant difference from actual biomass (Table 1). However, the scatter of the subsampling-foliar biomass estimates reveals the method's imprecision in estimating foliar biomass for individual trees (Figure 2c). The method might accurately estimate foliar biomass averages for a population of trees but is imprecise for individual trees. Due to estimation variability and the small sample size, attempts to relate estimates to a simple measure of dbh (the goal of testing these subsampling methods) were considered premature.

As an estimator of woody and total above-ground biomass, the subsampling method is more precise (Figure 3 ), producing slight over- or underestimates 
for 5 of 6 mulberry trees (Figure 3b). Plotted estimates for 5 of the 6 unpruned mulberries are either on or very near the 90-degree line (Figure 3b, d). The estimates for the 2 cherry trees cause concern. As mentioned previously, these 2 "outlying" estimates may have less to do with the method and more to do with arboricultural practices applied to the trees.

Pruning had noticeably changed the natural taper of one of the trees. At a height of $1.1 \mathrm{~m}(3.6 \mathrm{ft})$, the diameter of the bole decreased from 22.3 to $5.2 \mathrm{~cm}$ (8.8 to $2.0 \mathrm{in}$.) over a $30-\mathrm{cm}$ (11.8 in.) distance. The sampling conducted on both paths to determine where to cut disks for weighing resulted in both disks being cut near the bole of the tree. Neither disk was cut from a point above the sudden reduction in bole diameter. The result was that the subsampling method, which inflates the disk weight over the length of the selected paths, overestimated the woody dry weight of this tree several-fold. Pruning that radically alters natural tree architecture can limit the application of this and other methods in urban forests.

Surrogate method and comparison with subsampling. The surrogate method produced more precise individual estimates of foliar biomass than the subsampling method (Figure 2c, d). Because both methods are based on samples collected from each tree, why is one method more precise than the other? It is likely that the surrogate's increased precision is a function of a larger number of samples collected and the sampling locations within the tree crown. Surrogate estimates were calculated from a total of 6 paths, 2 each from the lower, middle, and top strata of the trees. The subsampling method does not require stratification and uses only 2 sampling paths. Further study of the surrogate method is warranted.

Nowak regression equation. Of the 4 methods used to estimate foliar biomass, only the Nowak method was developed using trees similar to those in our study. Nowak pooled data from 54 healthy, opengrown park trees representing 5 species growing in Chicago, Illinois, with Gacka-Grzesikiewicz's data on 34 smaller urban trees (12 species) from residential and park areas in Warsaw, Poland (Nowak 1996). Because of the sample similarity, one might expect this formula to produce better estimates than those methods developed using different tree populations and site conditions, yet it underestimated leaf biomass for 7 of the 8 trees (Figure 2b).

The shading factors we used may have been low and could have contributed to the underestimation of biomass. However, this is 1 of 2 factors in the Nowak formula where errors can be made in estimating foliar biomass. Crown shape $(C)$ and shading factor $(S)$ variables are fundamental for correct predictions, but both vary by individual and species. There are no standards for categorizing trees for measurement of either variable. Crown shape and foliage density may be altered radically by pruning practices. Also, little is known about variation in foliage due to variation in local site conditions, and this may contribute to error. Accuracy of estimates may have improved if we had measured shading factors for specific trees instead of using an estimated average for the species, but this type of data collection reduces the efficiency the method was designed to provide.

Interestingly, the Nowak method produced moreprecise estimates of the heavily pruned cherry trees ( $8 \%$ and $31 \%$ of actual) than the Harris method, perhaps a result of having been developed from urban trees. However, it was not as consistently accurate as the surrogate method ( $8 \%$ of actual for both trees).

Efficiency of sethods. The 2 allometric methods were the most efficient methods to apply, requiring the collection of basic tree measurement data (e.g., dbh, height, crown width). The Harris method was the more efficient of the 2 methods because it did not require a literature search or field measurements needed by the Nowak method to obtain shading coefficient datadata that are not available for many species.

The goal of using the subsampling and surrogate methods is ultimately to relate them to a measure of $\mathrm{dbh}$ alone. For the purpose of this pilot study, the sampling procedures were much more labor intensive than the allometric methods. On average, it took 2 hours to select 6 foliar paths per tree for the surrogate method and 45 minutes per tree to select the 2 subsampling paths. Depending upon the amount of foliage, cutting limbs, picking, and weighing all leaves on surrogatefoliar paths required anywhere from 1 to 3 hours per tree. Cutting the woody disks and weighing the terminal branches for the 2 subsampling paths took approximately 20 minutes per tree.

\section{Conclusions}

Despite the fact that the Harris, subsampling, and surrogate methods were developed for rural forest applications, our results showed that application to urban forests may be possible. Preliminary indications are that the Harris equation for predicting total aboveground biomass could be applied to lightly pruned or unpruned urban trees. Additional testing and analysis of the the method should be conducted to determine whether biomass partitioning can be adjusted to produce accurate individual estimates for foliar and woody biomass.

Subsampling biomass estimates showed no significant difference from actual foliar, woody, and total above-ground biomass. Plotting of individual tree fo- 
liar estimates, however, illustrates the method's imprecision for estimating individual tree foliar biomass. There are preliminary indications, through comparisons with surrogate-foliar method estimates, that precision could be improved by modifying the sampling method and incorporating stratified random sampling in the path selection procedure. Results also indicate that the method's applicability to intensely pruned trees for estimating woody and total above-ground biomass should be tested to determine to what extent changing tree architecture will affect estimation accuracy.

Surrogate-foliar biomass estimates were more precise than subsampling-foliar estimates, but remained significantly different from actual biomass. This was, however, the only method to produce foliar estimates for the heavily pruned cherry trees that were within $8 \%$ of measured biomass. The Nowak equation produced the next best cherry estimates $(8 \%$ and $31 \%$ of actual), but overall, the Nowak equation produced estimates significantly different from measured biomass.

In general, accurate estimates of mulberry biomass versus inaccurate cherry biomass estimates illustrate the problem of applying methods across species without further investigation of the variables influencing tree growth and biomass accumulation in urban settings. Genetics, climate, competition, site conditions, and arboricultural practices are a few of the variables impeding the direct transference of methods developed in traditional rural forestry. Furthermore, the lack of existing standards for categorizing urban trees for measurement remains problematical.

\section{Literature Cited}

Baskerville, G.L. 1972. Use of logarithmic regression in the estimation of plant biomass. Can. J. For. 2: 49-53.

Burkman, W.G., R. Anderson, K. Stolte, V.J. LaBau, I. Millers, M. Miller-Weeks, and M. Schomaker. 1993. Crown condition classification. In Conkling, B.L., and G.E. Byers (Eds.). Forest Health Monitoring Field Methods Guide, Internal report. US Environmental Protection Agency, Las Vegas, NV.

DeGier, A., and C. Kaboré. 1993. Woodland biomass assessment in Burkina Faso and the Netherlands, pp 145-152. In Wood, G.B., and H.V. Wiant, Jr. (Eds.). Modern Methods of Estimating Tree and Log Volume. Proceedings, IUFRO conference, June 14-16, 1993, West Virginia University Publications Services, Morgantown, WV.

Gacka-Grzesikiewicz, E. 1980. Assimilation surface of urban green areas. Ekol. Pol. 28(4):493-523.

Harris, W. F., Goldstein, R. A., and G. S. Henderson. 1973. Analysis of forest biomass pools, annual primary production and turnover of biomass for a mixed deciduous forest watershed, pp 41-64. In Young, H.E. (Ed.). IUFRO Biomass Studies: Nancy, France, and Vancouver, BC. Univ. Maine, Col. Life Sci. and Agric., Orono, ME.

Jo, H.K., and E.G. McPherson. 1995. Carbon storage and flux in urban residential greenspace. J. Env. Mgmt. 45:109-133.

McPherson, E.G., and P.L. Sacamano. 1992. Energy savings with trees in Southern California. Tech. rpt. USDA For. Serv. Pac. Southwest. Res. Sta., Western Ctr for Urban For. Res. $187 \mathrm{pp}$.

Nowak, D.J. 1994. Urban forest structure: The state of Chicago's urban forest, pp 83-94. In McPherson, E.G., D.J. Nowak, R.A. Rowntree (Eds.). Chicago's Urban Forest Ecosystem: Results of the Chicago Urban Forest Climate Project. USDA For. Serv. Northeast. For. Exp. Sta. Gen Tech Rpt. NE-186. Radnor, PA.

Nowak, D.J. 1996. Estimating leaf area and leaf biomass of open-grown deciduous urban trees. For. Sci. 42(4): 504507.

Peper, P.J., and E. G. McPherson. 1998. Comparison of five methods for estimating leaf area index of open-grown deciduous trees. J. Arboric. 24(2):98-111.

Rowntree, R.A., and D.J. Nowak. 1991. Quantifying the role of urban forests in removing atmospheric carbon dioxide. J. Arboric. 17:269-275.

Shinozaki, K., K. Yoda, K. Hozumi, and T. Kira. 1964. A quantitative analysis of plant form-the pipe model theory. 1. Basic analyses. Jpn J. Eco. 14(3):97-105.

Simpson, J.R., and E.G. McPherson. 1996. Estimating urban forest impacts on climate-mediated residential energy use, pp 462-465. In 12th Conference on Biometeorology and Aerobiology. American Meteorological Society. Boston, MA.

Soil Conservation Service. 1977. Soil survey of Solano Country, California. USDA Soil Conserv. Serv., Davis, CA. $65 \mathrm{pp}$.

Valentine, H.T., L.M. Tritton, and G.M. Furnival. 1984. Subsampling trees for biomass, volume, or mineral content. For. Sci. 30(3):673-681.

Valentine, H.T., V.C. Baldwin, Jr., T.G. Gregoire, and H.E. Burkhart. 1994. Surrogates for foliar dry matter in loblolly pine. For. Sci. 40(3):576-585.

Acknowledgments. This project would not have been possible without the assistance of Linda George, who maintains the Solano Urban Forest Research Site, and field technicians Uma Ramakrishnan, Richard Bagaoisan, Melissa Kaufman, Nina Luttinger, and Tin-Wah Wong. We especially thank Sylvia Mori and Harry Valentine for providing statistical and technical support that was critical to this study.

Western Center for Urban Forest Research \& Education Pacific Southwest Research Station

USDA Forest Service

c/o Department of Environmental Horticulture

One Shields Avenue

University of California

Davis, CA 95616-8587 
Résumé. Deux méthodes d'échantillonnages restreints et deux formules de régression ont été testées pour l'estimation de la biomasse foliaire, ligneuse et/ou totale de l'arbre avec huit arbres feuillus croissants en milieu ouvert. Les tests comparatifs de T n'ont montré aucune différence significative entre la méthode d'échantillonnage et les valeurs de biomasse foliaire, ligneuse et totale réelles. II n'y avait pas non plus de différence significative entre les estimés générés à partir d'une des formules de biomasse et la biomasse totale réelle. Cependant, un examen rapide de l'applicabilité des méthodes a montré un potentiel pour calibrer les résultats des deux équations de biomasse afin de produire des estimés précis de la biomasse des arbres urbains. D'autres tests sont nécessaires pour déterminer l'applicabilité des méthodes à un plus large éventail d'espèces et de sites de l'environnement urbain.

Zusammenfassung. Von acht freistehenden Laubbäumen wurde die aktuelle Biomasse mit Werten aus zwei Sammelmethoden und zwei Regressionsformeln zur Bestimmung von Laubmase, Holzmsse und/oder der ganzen oberirdischen Biomasse verglichen. Die gepaarten t-Tests zeigten keine signifikante Differenz zwischen der einen Sammelmethode und der aktuellen Blatt-, Holz- und oberirdischen Gesamtbiomasse. Es gab auch keine signifikante Differenz zwischen den Schätzungen aus einer Biomassenformel und der tatsächlichen oberirdischen Biomasse. Trotzdem zeigte eine visuelle Überprüfung der Anwendbarkeit dieser genannten Methoden, daß hier ein Potential besteht, um akurate Schätzungen der Biomasse von Stadtbäumen zu erhalten. Um die Anwendbarkeit der Methoden auf eine Reihe von Baumarten und Standorten zu bestimmen, sind weitere Testreihen notwendig.

Resumen. Se probaron dos métodos de submuestreo y dos fórmulas de regresión para estimación foliar, biomasa maderable y/o biomasa total arriba del terreno, contra la biomasa real de 8 árboles deciduos de crecimiento abierto. Pruebas de tapareadas no mostraron diferencia significativa entre uno de los métodos de submuestreo y el follaje real, biomasas maderable y total arriba del terreno. Tampoco hubo diferencia significativa entre las estimaciones generadas con una de las fórmulas de biomasa y la biomasa total arriba del terreno. Sin embargo, una inspección visual sobre la aplicabilidad de los métodos mostró potencial para la calibración de las respuestas en ambas ecuaciones para producir estimaciones precisas de biomasas de árboles urbanos. Se necesitan pruebas adicionales para determinar la aplicabilidad de los métodos a un rango de especies y sitios en el ambiente urbano. 